Forum

\title{
Body size and fitness in plants: Revisiting the selection consequences of competition
}

\author{
Lonnie W. Aarssen* \\ Department of Biology, Queen's University, Kingston, Ontario, Canada K7L 3N6
}

\section{A R T I C L E I N F O}

\section{Article history:}

Received 17 May 2014

Received in revised form 7 February 2015

Accepted 19 February 2015

Available online 27 February 2015

\section{Keywords:}

Competitive ability

Fecundity

Reproductive economy

Reproductive threshold size

Shade tolerance

Size-advantage

\begin{abstract}
A B S T R A C T
Having capacity for a relatively large plant body size is usually regarded as a key functional trait associated with success under competition between resident species within natural vegetation. This traditional 'size-advantage' hypothesis, however, generally fails to find support from several lines of recent research. Possible interpretations are considered here, including one in particular that has been largely overlooked: a larger species generally also needs to grow to a larger threshold size before it can reproduce at all, and the latter may not be generally attainable when neighbourhood resources are severely contested. The implications of this are explored in calling for a revised model of the selection consequences of competition on body size in plants, where success is defined not just (or even most importantly) by capacity to capture resources and deny them to neighbours, but more fundamentally by the capacity to transmit genes to future generations, despite severe resource deprivation by neighbours. For this latter capacity, a growing body of evidence is pointing to an alternative hypothesis based on 'reproductive economy advantage': under conditions of extreme and protracted neighbourhood crowding/competition (where virtually all resident plants are necessarily forced to remain, until death, at only a small fraction of their maximum potential body sizes), it is the relatively small species that are more likely to leave descendants here - simply because they need to reach only a relatively small body size in order to produce at least some offspring. Resident plants of most larger species, however, are more likely to die here producing none at all.
\end{abstract}

(C) 2015 Geobotanisches Institut ETH, Stiftung Ruebel. Published by Elsevier GmbH. All rights reserved.

\section{Introduction}

Within most natural vegetation, resources are routinely and strongly contested between near neighbours of both the same and different species. According to conventional theory, the selection consequences of this sustained competition have been interpreted mostly in terms of a 'size-advantage' hypothesis - i.e. under severe neighbourhood crowding/competition, natural selection generally favours capacity (through pre-emptive, rapid and/or prolonged resource capture) for growth to a body size that is relatively large (e.g. Grime, 1979; Keddy, 1989; Grace, 1990; Goldberg, 1996). The precise physiological and morphological mechanisms of resource competition (particularly below-ground) may not always be sizerelated (Craine, 2009). Nevertheless, since resources (water, soil nutrients, quanta of sunlight, etc.) are always spatially (and temporally) distributed, it follows that a plant occupying more space

\footnotetext{
* Tel.: +1 613533 6133; fax: +1 6135336617.

E-mail address: aarssenl@queensu.ca
}

(and over a longer time), both above and below ground, will generally be better equipped to acquire these resources and thus deny them to neighbours. An individual that manages to attain this relatively large body size (while neighbouring plants fail to do so) will thus, inevitably, be expected to achieve greater reproductive output.

Results from recent empirical research, however, call into question the size-advantage hypothesis. If larger plant species are generally expected to exclude smaller ones when there is persistent crowding/competition, then neighbouring species should generally be more similar in body size than would be expected by random assembly, based on the local species pool. Yet several studies have failed to find evidence for this, including in grasslands (Schamp et al., 2011), old-field vegetation (Schamp et al., 2008), wetlands (Weiher et al., 1998), temperate forests (Schamp and Aarssen, 2009), tropical forests (Swenson and Enquist, 2009), and coastal sand-dune succession (Waugh and Aarssen, 2012). Larger species in crowded woody vegetation (Keating and Aarssen, 2009), as well as in crowded herbaceous vegetation (Schamp et al., 2013; Aarssen et al., 2014), are not more likely than smaller 


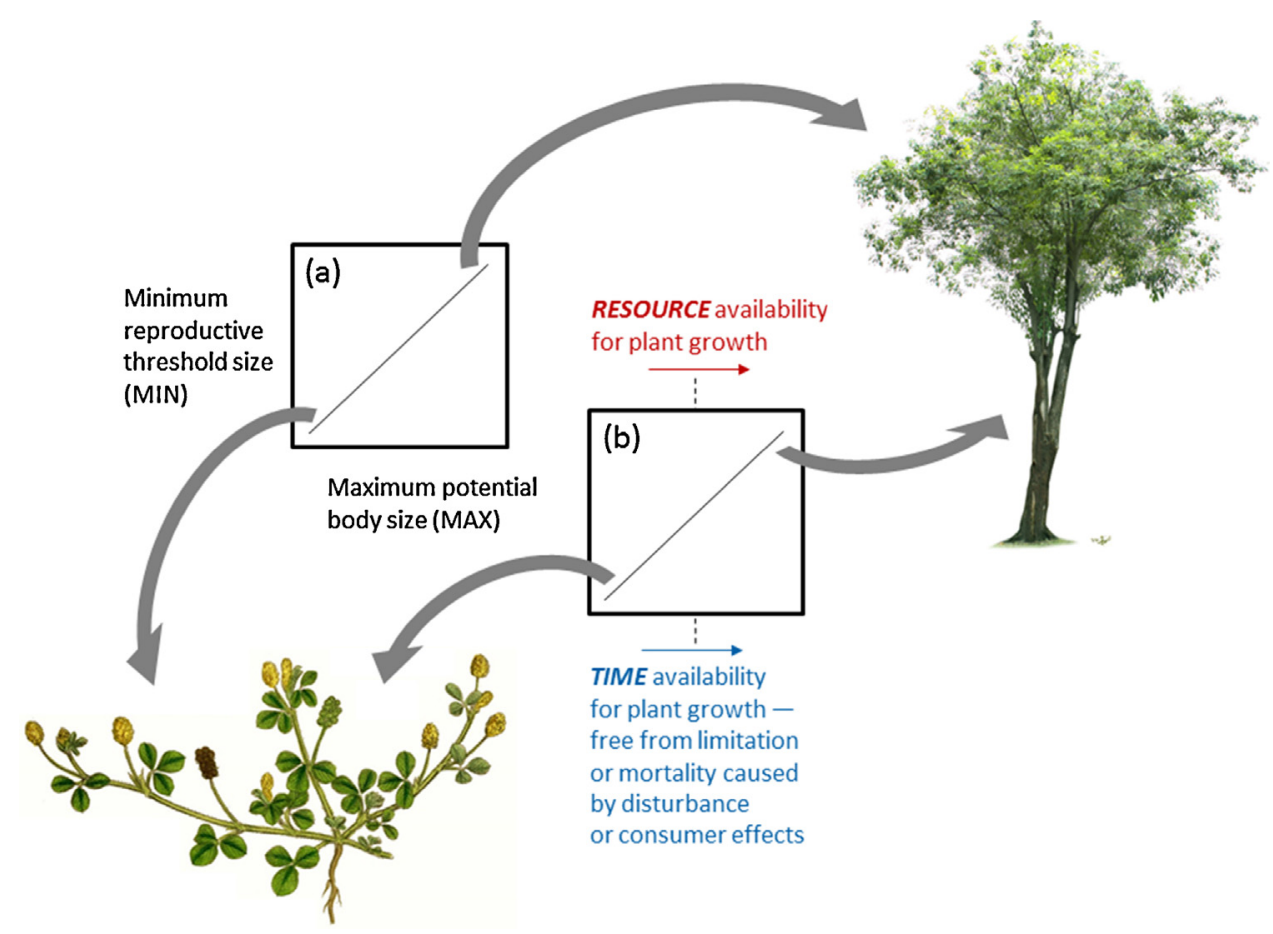

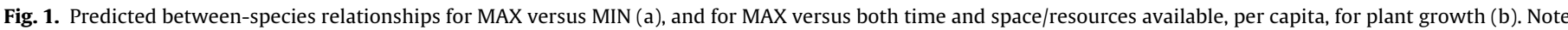

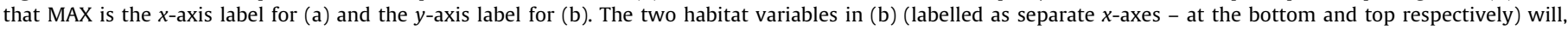
independently or simultaneously, constrain the typical upper limit of MAX for adapted (resident) species within different habitat types (see text).

species, to limit the resident species density within their immediate neighbourhoods, nor are they more likely to limit the representation of relatively small resident species. Bonser and Ladd (2011) similarly found that vegetative size was not a strong predictor of success under competition in annuals species; more important was the capacity to reproduce efficiently in the presence of competitors. Finally, a recent survey of published literature (Bonser, 2013) including for both short-lived semelparous and potentially longerlived iteroparous species - showed that the efficiency of conversion of resources from vegetative tissue to reproductive output is generally higher (not lower) when competition levels increase, contrary to traditional life history theory (see also Weiner et al., 2009).

When neighbourhood resources are strongly and persistently contested, therefore, there is apparently no general advantage (in terms of recruitment success or relative abundance within the habitat) for the offspring of species that are capable of (i.e. because they have evolved) relatively large potential body size (relative to the offspring of neighbouring species that have not evolved a large potential body size) (Tracey and Aarssen, 2011, 2014). The vast majority of plant species everywhere are in fact relatively small; i.e. plant species body size distributions are right-skewed within every phylogenetic lineage, and for resident species at every spatial scale - from regional floras down to local neighbourhoods (Aarssen and Schamp, 2002; Niklas et al., 2003; Aarssen et al., 2006; Poorter et al., 2008; Moles et al., 2009; Schamp and Aarssen, 2009; McGlone et al., 2010; Dombroskie and Aarssen, 2010; Tracey and Aarssen, 2011). And importantly this is also true even within habitat types traditionally characterized as having the strongest competition effects imposed on resident species.

The present objective of revising model predictions for body size evolution in plants begins with a now largely validated generalization: there is a fundamental between-species trade-off between maximum potential body size (MAX) and the capacity to reproduce when forced to remain small, i.e. minimum reproductive thresh- old size (MIN) (Fig. 1a). This has long been evident anecdotally for woody vegetation (and see Thomas, 1996; Davies and Ashton, 1999), but has only recently been reported from empirical studies in herbaceous vegetation, including for the resident species within a single community (Tracey and Aarssen, 2011, 2014; Nishizawa and Aarssen, 2014). This 'cost' of relatively large body size likely reflects the need for generally greater investment in structural support tissue, and also structural or chemical defense against consumers thus enabling the longevity (survival/growth time) needed in order to reach a large body size (Taylor et al., 1990). This has implications for the interpretation of body size variation not just between habitat types - but also within a single community of interacting species.

Herein then lies a profound and largely overlooked implication for plant competition theory: if a larger species generally also needs to grow to a larger threshold size before it can reproduce at all, the latter may not be generally attainable in neighbourhoods with severe and persistent crowding/competition. Larger species, therefore, can certainly be successful competitors in terms of denying contested resources to neighbours, but not if they are unable to get large. And there can be no fitness (gene transmission) advantage at all in having a large body size unless the plant can reach, at least, its relatively large MIN. Accordingly, as argued below, it turns out that larger resident species within a plant community are not usually superior competitors when it really matters - in the most severely crowded neighbourhoods.

\section{Body size limitations}

As a conceptual tool for moving forward with theory maturation, a simple graphical model can be used for representing how forces of natural selection affecting plant species body size are necessarily modulated by two distinct habitat features (Fig. 1b). Evolution of a larger MAX obviously requires capacity for greater growth, which will normally also require capacity for more resource capture. But 


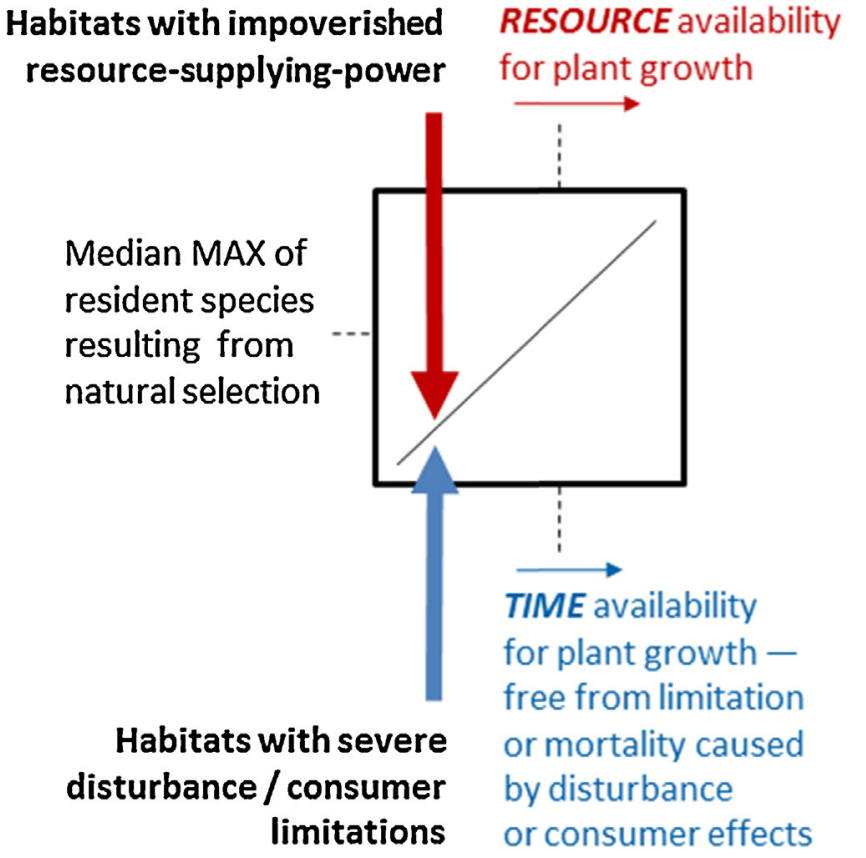

Fig. 2. Typical (median) relative MAX predicted (large arrows; resulting from natural selection) for resident plant species in habitats with impoverished resourcesupplying power, and habitats with severe disturbance/consumer limitations.

even more fundamentally, as a minimum, the greater growth necessary to achieve a larger MAX requires (on average, per capita) two things: (i) enough habitat resource-supplying-power (e.g. available energy/light, water, soil nutrients) to permit additional growth (upper $x$-axis in Fig. 1b); and (ii) enough time (to permit additional growth) that is relatively free from impacts of tissue loss or mortality risks from disturbance or consumer effects, at levels for which the plant's defense mechanisms are generally inadequate to permit recovery/survival (lower $x$-axis in Fig. 1b).

Accordingly, two largely undisputed predictions are derived from traditional plant life history theory (Harper, 1977; Grime, 1979; Tilman, 1988; Taylor et al., 1990), where relatively small body size resulting from natural selection is associated with two distinctly different habitat types: (i) where the resource-supplying-power of the habitat is relatively limited, e.g. resulting from soil resource impoverishment and/or climatic (temperature/precipitation) conditions that impose growing season limitation (e.g. tundra vegetation, desert annuals); and (ii) where there is relatively limited available time (for growth), that is free from risks of tissue loss or mortality caused by natural or anthropogenic disturbance or consumer effects (e.g. annuals and biennials in cultivated or roadside habitats; grassland vegetation and Mediterranean habitats limited by grazers, and/or fire - often exacerbated by precipitation impoverishment).

In both of these general habitat types - involving impoverishment and disturbance/consumer limitations respectively (or together) - the typical MAX of resident species is predicted to be relatively small (with generally very few woody species, or none at all) (Fig. 2). Fitness here is linked primarily to traits that confer tolerance of these limitations - which may also, but need not be, exacerbated by neighbourhood competition - with capacity to survive them long enough to produce offspring, or capacity to complete the life cycle before limitation becomes severe, e.g. as for annuals/biennials in periodically disturbed habitats. In the latter case, selection does not strongly favour allocation of resources/biomass needed for perennation and polycarpy (i.e. longevity, and hence size accumulation and reproduction across multiple growing seasons) because these would normally be 'wasted', owing to the high probability of early death. Fitness is promoted instead by investment in traits - including small MIN (and hence small MAX as a tradeoff; Fig. 2) - that confer successful reproductive output within the relatively narrow window of time available for growth and reproduction between mortality-causing, gap-creating events, or before crowding becomes intense following a gap-creating event (plus traits that confer successful offspring dispersal in time - seed dormancy, to 'sit and wait' for the next gapcreating event - and dispersal in space to other habitats affected by gap-creating events) (Harper, 1977; Grime, 1979; Tilman, 1988; Taylor et al., 1990).

In the case of habitat impoverishment, slow growth is literally enforced, and so selection generally also favours a relatively small MIN - thus maximizing the probability of reproduction before death, since large body size is virtually unattainable regardless of available time for growth. A relatively small MAX then results as a trade-off of this selection (Fig. 2), but is also limited directly by habitat impoverishment itself. In grasslands, where (even if growth happens not to be limited significantly by habitat resource impoverishment, nor by competition), selection also favours a relatively small MIN because this maximizes the probability of offspring production (sexually or clonally) within the often narrow window of time between episodes of tissue loss from grazers or fire. A relatively small MAX then results again as a trade-off of this selection, but is also limited directly by the predictably regular effects of tissue loss itself.

\section{Body size and competition}

With the exception of annuals and biennials considered above, a relatively small MIN need not necessarily be associated with quick (early) reproduction or a particularly short lifespan. Importantly, as argued below, a relatively small MIN (and hence small MAX as a trade-off) need not even be associated with habitat impoverishment limitation, or disturbance/consumer limitations. Even within habitat types defined be these limitations, species body sizes, although relatively small on average, nevertheless commonly vary by at least an order of magnitude, and usually with a right-skewed distribution. The latter is also particularly true within habitat types distinctly different from the two described above i.e. where growth of most resident plants/species is not severely limited by available time that is free from high risk of tissue loss or mortality caused by large-scale disturbance/consumer effects. Nor is growth severely limited by the resource-supplying-power of the habitat (e.g. soil fertility, growing-degree days). The model in Fig. 1b illustrates that these are the habitat conditions necessary to support the growth needed to attain a particularly large MAX, and these are indeed the habitat types where the largest species are found - in woodlands with deep, mesic, fertile soils.

Under these latter habitat conditions, also represented by many mid-successional shrublands and old-fields, the fitness of a plant is expected traditionally to be connected primarily with one, or both, of two components: (i) its capacity - involving niche differentiation mechanisms - to avoid or limit interaction with superior resource competitors (e.g. by temporal or spatial separation of resource use); or, (ii) its capacity to be a successful resource competitor, against both inter- and intra-specific neighbours. The latter case is of particular interest here, where - according to the traditional size-advantage hypothesis - selection especially favours capacity for relatively large MAX because of its potential advantage in denying contested resources to neighbours, e.g. because they are shaded (Grime, 1979; Goldberg, 1996; Craine, 2009). But also (even more fundamentally), because a larger body size - both within- and between-species - will, all else being equal, usually be 


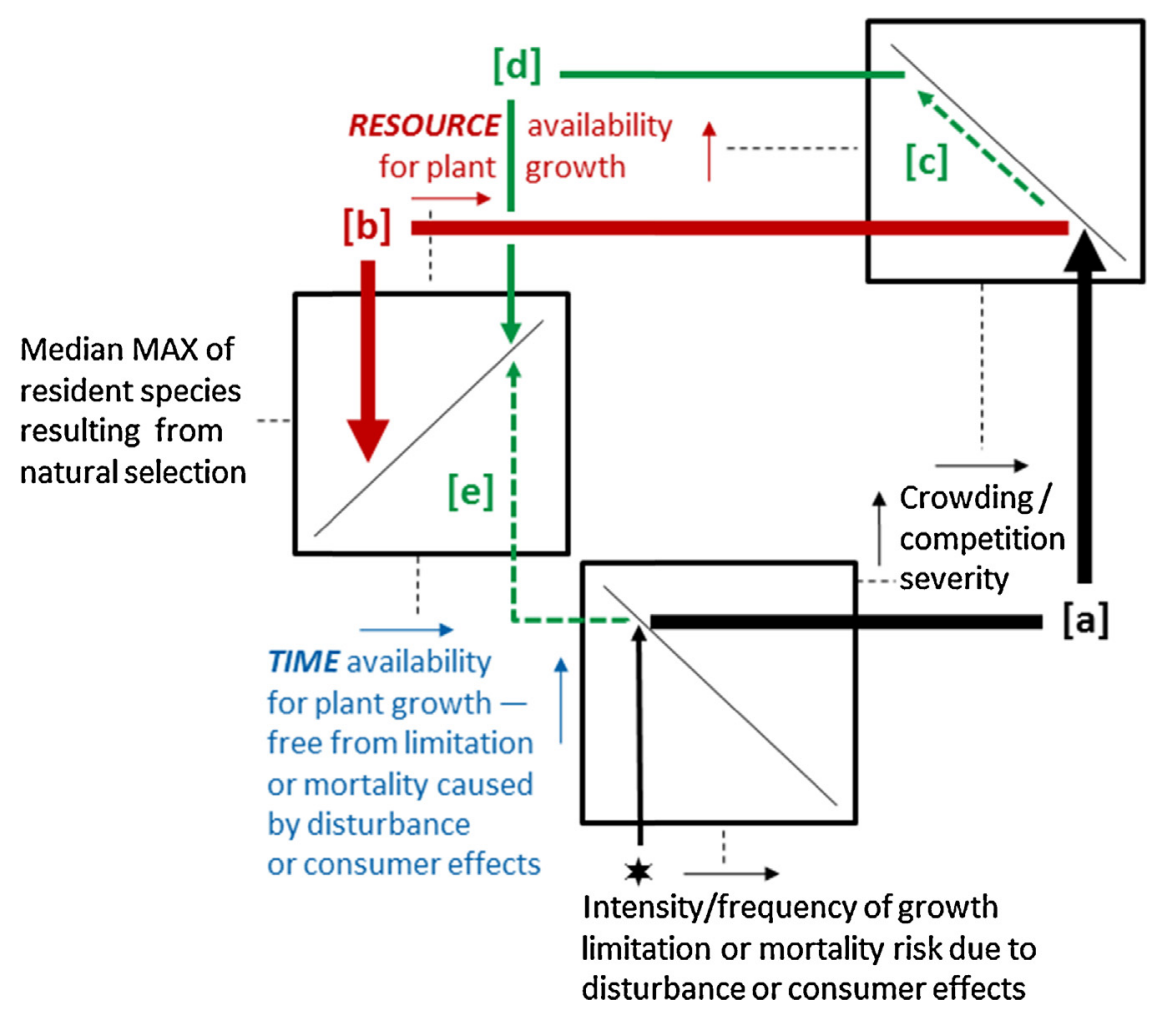

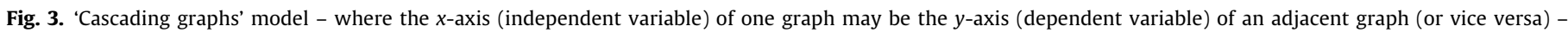

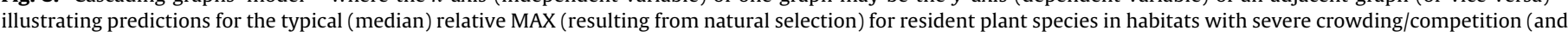

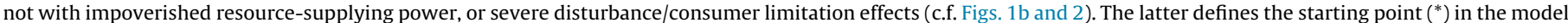

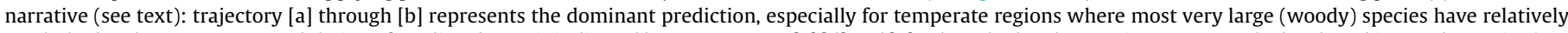

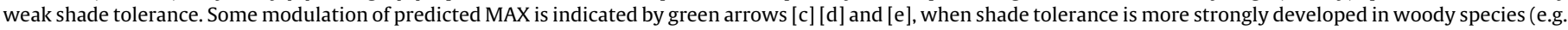

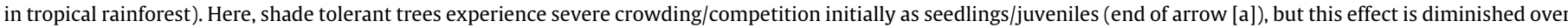

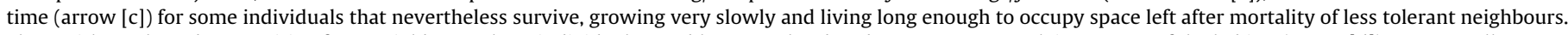

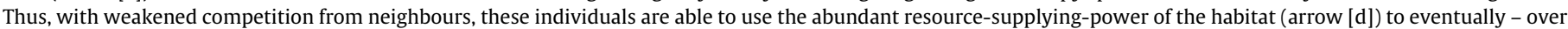
the available time (arrow [e]) - reach their large MAX (see text).

associated with higher fecundity. Accordingly, capacity for more growth (through successful resource capture), including to a relatively large MAX, has been interpreted, in a large body of literature, as the principal trait for defining competitive ability and hence the principal plant strategy promoting transmission of gene copies into future generations when resources are severely contested (Aarssen and Keogh, 2002).

However, a paradox looms: a relatively large MAX can certainly define superior ability to deny contested resources to neighbours, as well as ability to avoid being denied resources by neighbours; a taller plant shades more and also gets shaded less. But reaching a relatively large MAX will generally require relatively weak neighbourhood crowding effects - and the latter are particularly unlikely to be associated with resource-rich/low-disturbance habitats. Accordingly, the vast majority of resident species here do not have large MAX at all, and yet ironically the vast majority of relatively large species, worldwide, are associated exclusively with this habitat type.

This disconnect with the size-advantage hypothesis has at least one of three profound implications that remain largely untested and unresolved: (i) deprivation of resources from neighbour effects is not as limiting (e.g. compared with disturbance or consumer effects) as is usually assumed for crowded vegetation in relatively resource-rich habitats; (ii) the impact of resource competition between small and large species within such vegetation is relatively weak because of niche differentiation mechanisms and/or opportunities for concurrent facilitation effects that are still poorly understood - e.g. small and large species may have different 'physical space' niches, with larger species harvesting resources less efficiently (per unit space occupied) (Aarssen et al., 2006), and with larger species also possibly suffering greater intra-specific density-dependent mortality (Schamp and Aarssen, 2014), with limited capacity therefore to competitively exclude smaller species, since the latter can more easily invade pure stands of larger species (Schamp and Aarssen, 2010); (iii) relatively small plant body size contrary to traditional theory - does not impose inferior capacity to transmit gene copies to future generations when resources are strongly contested by neighbourhood crowding/competition.

The first two hypotheses above derive from well-established theory based on mechanisms in which contemporary selection associated with crowding/competition between species is considered weak (and hence relatively unimportant), either because of non-equilibrium conditions (where densities and/or community biomass are kept - or regularly return to - below carrying capacity because of disturbance or consumer effects), or because of species assembly structured by niche differentiation (which may have evolved earlier as a consequence of past competition). Hypothesis (iii) above, however, has been largely ignored within plant competition theory - and only it (and not the other two hypotheses) assumes that both past and current selection from crowding/competition between species (as well as within species) is significant, and with consequences therefore, that have shaped (and continue to shape) the distribution of plant functional traits. Hypothesis (iii) is thus considered below in developing revised 
model predictions for effects of this selection on plant species body size in particular.

The revised model (Fig. 3) begins with the effect of a relatively low per capita probability of growth limitation or mortality from disturbance/consumer effects. This of course increases time availability for plant growth (free from limitation or mortality caused by disturbance or consumer effects) (left $y$-axis in the bottom graph of Fig. 3). But at the same time, it also allows relatively high levels of neighbourhood crowding/competition between resident plants (both above and below ground) to escalate and persist (right $y$-axis in the bottom graph of Fig. 3). The latter effect - arrow [a] - in turn decreases per capita space/resource availability - arrow [b] (Fig. 3). Hence, while growing in a habitat with high resource-supplying growing, a resident plant here nevertheless experiences the habitat as though it were severely impoverished.

The predictions that follow thus depend significantly upon the extent to which there is capacity for tolerance of this resource depletion by neighbours (particularly shade-tolerance, when resource-supplying-power of the habitat is high). If a species here has a relatively large MAX (i.e. relative to other resident species) but little or no shade tolerance (e.g. as in most herbaceous vegetation), only a very few resident plants will (by chance on a local scale, within some of the very few neighbourhoods that happen to be relatively uncrowded/unshaded) - be spared the above resource limitation, and thus be capable of achieving something approaching their large MAX (and hence with fitness returns from associated investments in structural support and defense). Most resident plants however, will not escape these suppressive effects of severe crowding/competition; they will die without reproduction - and especially if they have a relatively large MAX, because this means that they will generally fail to reach their large MIN before death (c.f. the trade-off in Fig. 1a).

The central prediction represented in Fig. 3 may be best envisaged by considering the probable fates of offspring from small and large species that all start at essentially the same size, as embryos within seeds that germinate together at high density, and with severe crowding therefore from both intra- and interspecific neighbours, and possibly also resource deprivation (e.g. shading) effects from larger neighbours, including parent plants. The model (again assuming little or no shade-tolerance) predicts that the offspring of smaller species are generally more likely to produce grandoffspring for the next generation, mainly because smaller species have generally greater 'reproductive economy' - i.e. they need to reach only a relatively small body size in order to achieve at least some reproduction (Aarssen, 2008). The relatively large species here are unable to get large (being mostly forced by severe crowding, from both intra- and inter-specific neighbours, to remain as suppressed weaklings) and so they are generally unlikely to have an advantage in terms of resource capture or growth rates. The most successful of these neighbours may be strong competitors for below ground resources - in terms of capacity (per unit root mass or surface area) to extract available soil nutrients or water (Craine, 2009), but there is no reason to expect this capacity to be superior for larger species. Previous analyses have shown in fact that larger species generally have slower growth rates (Enquist et al., 1998) (which, in some cases, may be associated with capacity for extended survival attributed to tolerance of resource depletion/deprivation, e.g. shade tolerance - see below). In addition, while larger species tend to produce larger seeds (Moles et al., 2004; Aarssen, 2005a), and this may confer superior growth capacity during seedling competition, there is little evidence that this advantage generally translates to superior competitive fitness (Moles and Westoby, 2004). This is because larger seed size comes at a cost of proportionately smaller lifetime seed offspring production per unit lifetime vegetative mass production (Aarssen and Jordan, 2001).

\section{Towards a paradigm shift}

The above arguments point to a paradigm shift from the traditional size-advantage hypothesis, thus providing a plausible general hypothesis for why most resident plant species are relatively small within habitat types where resources are most strongly contested. Because “... plant size has a positive genetic correlation with reproductive size threshold, then a larger species is predicted to have greater fecundity at older ages or lower densities, but a smaller species is predicted to have greater fecundity at younger ages or higher densities" (Aarssen, 2005b, p. 229). In other words, within habitats where resources are severely and persistently (most of the time) contested within the majority of neighbourhoods - and where virtually all resident plants are necessarily forced, therefore, to remain (until death) suppressed to only a small fraction of MAX - it is the relatively small, not large, species that are likely to leave the most descendants. It is important to emphasize that this prediction applies regardless of the resource-supplying-power of the habitat - and hence regardless of the median MAX of resident species.

Even where the largest plant species are found - trees within woodlands - they are vastly and routinely outnumbered (both in terms of species abundance and within-species plant abundance) by much smaller resident species (Condit, 1988; McCarthy and Bailey, 1996; Goodburn and Lorimer, 1999; Svensson and Jeglum, 2001; Muller-Landau et al., 2006) - many with shade tolerance but all of them with small MIN, including through vegetative (clonal) reproduction. Even among these many understory species that suffer resource competition with each other (within overlapping niches that in many cases may be created by the larger trees), species body size distributions are typically strongly right-skewed (Aarssen et al., 2006). The same has been reported for resident species within herbaceous plant communities (Tracey and Aarssen, 2011). Many relatively small species here may combine their small MIN with tolerance for water or nutrient deprivation/depletion by neighbours, and thereby endure (avoid mortality) long enough to produce at least some offspring (despite remaining as a suppressed weakling) - just as a small boxer may win against a bigger one if the former is better at withstanding the impact of punches (Aarssen, 1989). 'Enduring for longer' also means that space is occupied for longer, which in turn means that the plant (without needing to have a large MAX) may deny establishment space to the offspring of neighbours.

In temperate regions, trees (especially those in the largest size classes) are (with few exceptions) relatively shade intolerant and aclonal (Burns and Honkala, 1990; Ninemets and Valladares, 2006). Consequently, although represented in the canopy, they have relatively poor local offspring recruitment beyond the seedling/juvenile stages within mature woodland, and hence (compared with smaller species) their populations have relatively few resident reproductive plants in total. This of course begs the question: if these very large species have such inferior competitive fitness, why do they reside at all in these crowded communities? A likely explanation is because a very small proportion of a large tree's offspring manage fortuitously, from time to time, to establish as seedlings within rare, relatively uncrowded local neighbourhoods, with opportunity to grow - relatively free from suppression by overtopping neighbours - to a body size that can approach their large MAX, thus conferring very high fecundity iterated across a very long life span. Such a large tree - which is mostly dead biomass (wood) - will of course (through uptake and storage) control a relatively large fraction of habitat resources, and thus deny these contested resources to many smaller neighbouring species. But virtually all of its establishing offspring (i.e. that manage to escape from specialized consumers) never escape from suppression caused by neighbours here. Consequently, they remain as sup- 
pressed weaklings and eventually die without sex because of their large MIN, and so without producing 'grand-offspring' for the large parent tree.

Large species exist therefore not generally because they are superior competitors, but because neighbourhood competition is occasionally weak (even in the most crowded vegetation), and so they are occasionally able to get large (and long-lived, with high life-time fecundity). Capacity for relatively large body size (i.e. relative to other resident species within the community) then should promote gene transmission success across multiple generations only when there is some probability (within each generation) that at least some offspring can actually achieve something approaching this relatively large potential body size. In habitats where this probability is low (but not zero), this success is therefore achieved for many large plant species because some individuals (particularly through the juvenile life stages) manage to avoid severe competition - i.e. they find themselves, fortuitously, within local neighbourhoods (available only rarely, but 'often enough') where effects of crowding/competition (from both the same and different species) are relatively weak.

Extinction of these species is thus avoided, possibly in some cases because of niche requirements that differ from other (including smaller) species. But more commonly, I suggest, it is because even though competition may be severe within overlapping niches - an individual can, on average, never leave more than one descendant, and only one descendant is needed to have fitness greater than zero (which is always the fate of the vast majority of resident plants within vegetation). And the probability of leaving (at least) one descendant is virtually ensured by the massive lifetime fecundity attainable when a massive MAX can be approached - albeit only rarely by a miniscule proportion of resident plants that fortuitously begin life as establishing seedlings within neighbourhoods that end up being relatively uncrowded, together with sufficient habitat resource-supplying-power and sufficient disturbance-/consumerfree time to permit growth to a large MAX (i.e. the top right corner in Fig. 1b). Importantly then, the gene transmission success represented by this 'one descendant', in most cases is unlikely to be accounted for by competitive fitness attributed to any 'size advantage' for these large species. Rather, because of their large MIN (Fig. 1a), more likely this 'one descendent' mostly represents inheritance from a long lineage of ancestors that managed - by chance, locally - to enjoy the relatively low levels of neighbourhood crowding/competition needed to approach their large maximum potential body sizes.

Most of the relatively rare woodland neighbourhoods permitting opportunity to approach the relatively large MAX of shade-intolerant trees are likely to be created after a particularly large individual dies. But the death of most large canopy trees is usually attributed only secondarily - not directly - to cumulative effects of competition, nor to cumulative effects of impoverishment or consumers (except in relatively rare cases of severe outbreaks of specialized insects/pathogens). More commonly, the large canopy tree eventually just gets 'too big for its own good', imposing hydraulic and carbon balance limitations plus mechanical limitations, where the tree literally starts to collapse from the sheer weight of itself (especially with compounding effects from strong winds or snow/ice loading). Only then - in a weakened and subordinate condition - does the tree become more susceptible to exacerbation from impacts of taller neighbours, consumers, disease, rot, and senescence (Larson, 2001; Mencuccini et al., 2005).

Large woody species with very effective shade tolerance, however - as in Acer sacharrum in eastern North America for example, and as is in tropical rainforests more generally - can 'bide their time' within severely crowded neighbourhoods, surviving almost dormant or growing extremely slowly while 'waiting' for canopy gaps. Such individuals can thus eventually become less limited by crowding/competition (arrow [c] in Fig. 3) and so obtain enough resources/space (arrow [d]) to allow - over the available time (arrow [e]) - approach to their relatively large MAX. Importantly, then, the large body sizes attained by these species, rather than a principal strategy for competitive ability (fitness under severe competition), instead actually requires some measure of release from severe competition. Most resident species in tropical rainforest still have relatively small MAX (also with shade tolerance), but greater shade tolerance here in woody species (perhaps linked to less deciduousness?) can account for why there is a higher concentration here of relatively large species (trees) - with less right-skewed body size distributions - compared with temperate forests (Moles et al., 2009).

\section{Conspectus}

Having capacity for growth to a large plant body size will normally be a poor predictor of gene transmission success under competition - contrary to traditional theory. In most natural vegetation, a large MAX (and its attendant high fecundity), can be achieved only within relatively uncrowded local neighbourhoods. Several lines of evidence now indicate that, when resources are strongly contested, success in transmitting gene copies to future generations, has been generally more successful (over evolutionary time) in association with relatively small (not large) plant body size, with consequently greater incidence of new species origination (of descendant species, also relatively small) (Dombroskie and Aarssen, 2010). The key functional trait appears to be 'reproductive economy' - i.e. capacity, mainly because of small MIN, to produce offspring that can survive long enough to produce at least some grand-offspring, while nevertheless remaining with a severely suppressed body size (imposed by crowding/competition), even until death (Aarssen, 2008). Additional data from future studies are required to provide adequate tests of the above predictions for Fig. 3, and associated parameterisation for quantitative modelling.

\section{Acknowledgements}

Helpful comments on the manuscript were provided by Stephen Bonser, Rob Brooker, Joseph Craine, Jason Fridley, Angela Moles, Brandon Schamp, Mark Vellend, and Scott Wilson. Financial support was provided by a Discovery grant from the Natural Sciences and Engineering Research Council of Canada.

\section{References}

Aarssen, L.W., 1989. Competitive ability and species coexistence: a 'plant's eye' view. Oikos 56, 386-401.

Aarssen, L.W., 2005a. Why don't bigger plants have proportionately bigger seeds? Oikos 111, 199-207.

Aarssen, L.W., 2005b. On size, fecundity and fitness in competing plants. In: Reekie, E., Bazzaz, F.A. (Eds.), Reproductive Allocation in Plants. Elsevier, New York, pp. 215-244.

Aarssen, L.W., 2008. Death without sex - the 'problem of the small' and selection for reproductive economy in flowering plants. Evol. Ecol. 22, 279-298.

Aarssen, L.W., Jordan, C.Y., 2001. Between-species patterns of covariation in plant size, seed size and fecundity in monocarpic herbs. Ecoscience 8, 471-477.

Aarssen, L.W., Keogh, T., 2002. Conundrums of competitive ability in plants: what to measure? Oikos 96, 531-542.

Aarssen, L.W., Schamp, B.S., 2002. Predicting distributions of species richness and species size in regional floras: applying the species pool hypothesis to the habitat template model. Perspect. Plant Ecol. Evol. Syst. 5, 3-12.

Aarssen, L.W., Schamp, B.S., Pither, J., 2006. Why are there so many small plants? Implications for species coexistence. J. Ecol. 94, 569-580.

Aarssen, L.W., Schamp, B.S., Wight, S., 2014. Big plants - do they affect neighbourhood species richness and composition in herbaceous vegetation? Acta Oecol. $55,36-42$

Bonser, S.P., 2013. High reproductive efficiency as an adaptive strategy in competitive environments. Funct. Ecol. 27, 876-885. 
Bonser, S.P., Ladd, B., 2011. The evolution of competitive strategies in annual plants. Plant Ecol. 212, 1441-1449.

Burns, R.M., Honkala, B.H., 1990. Silvics of the North America. Agriculture Handbook 654, vols. 1-2. United States Department of Agriculture Forest Service, Washington, DC.

Condit, R., 1988. Tropical Forest Census Plots. Springer-Verlag/R.G. Landes, USA.

Craine, J.M., 2009. Resource Strategies of Wild Plants. Princeton University Press, Princeton.

Davies, S.J., Ashton, P.S., 1999. Phenology and fecundity in 11 sympatric pioneer species of Macaranga (Euphorbiaceae) in Borneo. Am. J. Bot. 86, $1786-1795$.

Dombroskie, S.L., Aarssen, L.W., 2010. Within-genus size distributions in angiosperms: small is better. Perspect. Plant Ecol. Evol. Syst. 12, 283-293.

Enquist, B.J., Brown, J.H., West, G.B., 1998. Allometric scaling of plant energetics. Nature 395, 163-165.

Goodburn, J.M., Lorimer, C.G., 1999. Population structure in old-growth and managed northern hardwoods: an examination of the balanced diameter distribution concept. For. Ecol. Manage. 118, 11-29.

Grace, J.B., 1990. On the relationship between plant traits and competitive ability. In: Grace, J.B., Tilman, D. (Eds.), Perspectives on Plant Competition. Academic Press, San Diego, TX, pp. 384-385.

Goldberg, D.E., 1996. Competitive ability: definitions, contingency and correlated traits. Proc. R. Soc. B: Biol. Sci. 35, 1377-1385.

Grime, J.P., 1979. Plant Strategies and Vegetation Processes. Wiley, New York.

Harper, J.L., 1977. Population Biology of Plants. Academic Press, London.

Keating, L.M., Aarssen, L.W., 2009. Big plants - do they limit species coexistence? J. Plant Ecol. 2, 119-124.

Keddy, P.A., 1989. Competition, 2nd edition. Chapman and Hall, New York, pp. 202 pp.

Larson, D.W., 2001. The paradox of great longevity in a short-lived tree species. Exp. Gerontol. 36, 651-673.

McCarthy, B.C., Bailey, D.R., 1996. Composition, structure and disturbance history of crabtree woods: an old growth forest of western Maryland. Bull. Torrey Bot. Club 123, 350-365.

McGlone, M.S., Richardson, S.J., Jordan, G.J., 2010. Comparative biogeography of New Zealand trees: species richness, height, leaf traits and range sizes. N. Z. J. Ecol. 34, 137-151.

Mencuccini, M., Martinez-Vilalta, J., Vanderklein, D., Hamid, H.A., Korakaki, E., Lee, S., et al.,2005. Size-mediated aging reduces vigour in trees. Ecol. Lett. 8, 1183-1190.

Moles, A.T., Westoby, M., 2004. Seedling survival and seed size: a synthesis of the literature. J. Ecol. 92, 372-383.

Moles, A.T., Falster, D.S., Leishman, M.R., Westoby, M., 2004. Small-seeded species produce more seeds per square metre of canopy per year, but not per individual per lifetime. J. Ecol. 92, 384-396.

Moles, A.T., Warton, D.I., Warman, L., Swenson, N.G., Laffan, S.W., Zanne, A.E., Pitman, A., Hemmings, F.A., Frank, A., Leishman, M.R., 2009. Global patterns in plant height. J. Ecol. 97, 923-932.

Muller-Landau, H.C., Condit, R.S., Harms, K.E., 2006. Comparing tropical forest tree size distributions with the predictions of metabolic ecology and equilibrium models. Ecol. Lett. 9, 589-602.
Niklas, K.J., Midgley, J.J., Rand, R.H., 2003. Size dependent species richness: trends within plant communities and across latitude. Ecol. Lett. 6, 631-636.

Ninemets, U., Valladares, F., 2006. Tolerance to shade, drought, and waterlogging of temperate northern hemisphere trees and shrubs. Ecol. Monogr. 76, 521-547.

Nishizawa, T., Aarssen, L.W., 2014. The relationship between individual seed quality and maternal plant body size in crowded herbaceous vegetation. J. Plant Ecol., http://dx.doi.org/10.1093/jpe/rtt042.

Poorter, L., Hawthorne, W., Bongers, F., Sheil, D., 2008. Maximum size distributions in tropical forest communities: relationships with rainfall and disturbance. J. Ecol. 96, 495-504.

Schamp, B.S., Aarssen, L.W., 2009. The assembly of forest communities according to maximum species height along resource and disturbance gradients. Oikos 118, 564-572.

Schamp, B.S., Aarssen, L.W., 2010. The role of plant species size in invasibility: a field experiment. Oecologia 162, 995-1004.

Schamp, B.S., Aarssen, L.W., 2014. Plant species size and density-dependent effects on growth and survival. J. Veg. Sci. 25, 657-667.

Schamp, B.S., Chau, J., Aarssen, L.W., 2008. Dispersion of traits related to competitive ability in an old-field plant community. J. Ecol. 96, 204-212.

Schamp, B.S., Hettenbergerová, H., Hájek, M., 2011. Testing community assembly predictions for nominal and continuous plant traits in species-rich grasslands. Preslia 83, 329-346.

Schamp, B.S., Aarssen, L.W., Wight, S., 2013. Effects of 'target' plant species body size on neighbourhood species richness and composition in old-field vegetation. PLOS ONE 8 (12), e82036, http://dx.doi.org/10.1371/journal.pone.0082036.

Svensson, J.S., Jeglum, J.K., 2001. Structure and dynamics of an undisturbed oldgrowth Norway spruce forest on the rising Bothnian coastline. For. Ecol. Manage. 151, 67-79.

Swenson, N.G., Enquist, B.J., 2009. Opposing assembly mechanisms in a Neotropica dry forest: implications for phylogenetic and functional community ecology. Ecology 90, 2161-2170.

Taylor, D.R., Aarssen, L.W., Loehle, C., 1990. On the relationship between r/K selection and environmental carrying capacity: a new habitat templet for plant life history strategies. Oikos 58, 239-250.

Thomas, S.C., 1996. Relative size at onset of maturity in rain forest trees: a comparative analysis of 37 Malaysian species. Oikos 76, 145-154.

Tilman, D., 1988. Plant Strategies and the Dynamics and Structure of Plant Communities. Princeton University Press, Princeton.

Tracey, A.J., Aarssen, L.W., 2011. Competition and body size in plants: the between-species trade-off in maximum potential versus minimum reproductive threshold size. J. Plant Ecol. 4, 115-122.

Tracey, A.J., Aarssen, L.W., 2014. Revising traditional theory on the link between plant body-size and fitness under competition: evidence from old-field vegetation. Ecol. Evol. 4, 959-967.

Waugh, J.M., Aarssen, L.W., 2012. Size distributions and dispersions along a 485-year chronosequence for sand dune vegetation. Ecol. Evol. 2, 719-726.

Weiher, E., Clarke, G.D.P., Keddy, P.A., 1998. Community assembly rules, morphological dispersion, and the coexistence of plant species. Oikos 81, 309-322.

Weiner, J., Campbell, L.G., Pino, J., Echart, L., 2009. The allometry of reproduction within plant populations. J. Ecol. 97, 1220-1233. 